\title{
A CIRANDA INFANTIL NA VISÃO DE CRIANÇAS DE UM ASSENTAMENTO RURAL VINCULADO AO MST
}

\author{
THE CHILDREN'S CIRANDA BY THE VIEW OF CHILDREN FROM A RURAL SETTLEMENT \\ LINKED TO THE LANDLESS WORKERS' MOVEMENT (MST)
}

LA CIRANDA INFANTIL DESDE LA MIRADA DE NIÑOS DE UN ASENTAMIENTO RURAL DEL MST

\author{
Regiane Sbroion de Carvalho* \\ Wisner Tahan Filho ${ }^{* *}$ \\ Ana Paula Soares da Silva**
}

\begin{abstract}
RESUMO
A pesquisa objetivou compreender as significações de crianças de um assentamento rural vinculado ao MST, na região de Ribeirão Preto-SP, acerca de um espaço/tempo especificamente a elas destinado, denominado Ciranda Infantil. Utilizamos como instrumentos diário de campo, fotografias realizadas pelas crianças, conversas baseadas em fotografias, fantoches. Participaram seis crianças de 10 a 12 anos. Os resultados indicam que a Ciranda tem sido significada pelas crianças como um espaço de socialização e aprendizagens variadas entre adultos e crianças, marcadas pela construção de relações afetivas, socioambientais e geracionais, com destaque para a ludicidade. Conclui-se que as crianças percebem que existe para elas um projeto intencional e apropriam-se desse espaço como sujeitos críticos que colaboram em sua construção e, ou, disputam-no com os adultos. Esse sentimento de ter a Ciranda como espaço próprio os autoriza a propor melhorias para sua realização.
\end{abstract}

Palavras-chave: Criança. Ciranda infantil. Pesquisa com crianças. Rural. Movimento dos Trabalhadores Rurais Sem-Terra.

\footnotetext{
ABSTRACT

This research aimed to understand the meanings yielded by children of a rural settlement linked to the Landless Workers' Movement (MST), in the region of Ribeirão Preto (SP, Brazil), about a space/time assigned specifically to them, called Children's Ciranda. As methodological instruments, we

Texto recebido em 25 de agosto de 2015 e aprovado para publicação em 15 de setembro 2016.

Fontes financiadoras: Pró-Reitoria de Pesquisa da Universidade de São Paulo, Conselho Nacional de Desenvolvimento Científico e Tecnológico (CNPq).

Doutora pelo Departamento de Psicologia da Faculdade de Filosofia, Ciências e Letras de Ribeirão Preto, da Universidade de São Paulo; docente na Faculdade de Educação da Universidade do Estado do Rio de Janeiro. E-mail: resbroion@yahoo.com.br. Endereço: Avenida Caramuru, 1280, ap. 128, Ribeirão Preto-SP, Brasil. E-mail: resbroion@yahoo.com.br.

* Graduando em Psicologia na Faculdade de Filosofia, Ciências e Letras de Ribeirão Preto, da Universidade de São Paulo. E-mail: wisner_tf@yahoo.com.br.

"** Docente no Curso de Psicologia da Faculdade de Filosofia, Ciências e Letras de Ribeirão Preto, da Universidade de São Paulo. E-mail: apsoares.silva@usp.br.
} 
used field diary, photographs taken by the children; conversations based on the photographs; and puppets. Six children aged from ten to twelve years participated. The results indicate that "Ciranda" has been signified by children as a space of socialization and varied learnings among adults and children, marked by the construction of affective, socio-environmental and generational relations, highlighting playfulness. We conclude that children realize that there is an intentional project for them and they take property of this space as critical subjects who collaborate in its construction and / or compete with adults. This feeling of having the "Ciranda" as their own space authorizes them to propose improvements to its realization.

Keywords: Child. Children's ciranda. Research with children. MST (Landless Workers' Movement).

\section{RESUMEN}

La investigación tuvo como objetivo comprender los significados de los niños de un asentamiento rural vinculado al MST, en Ribeirão Preto (SP), acerca de un espacio / tiempo destinado específicamente hacia ellos, llamado "Ciranda Infantil". Se utilizó como instrumentos: diario de campo; fotografías tomadas por los niños; conversaciones acerca de las fotografías y marionetas. Participaron seis niños de diez a doce años. Los resultados indican que la "Ciranda" ha sido significada por los niños como un espacio de socialización y aprendizajes variados entre adultos y niños, así como marcada por la construcción de relaciones afectivas, ambientales y generacionales, destacando su carácter lúdico. Llegamos a la conclusión de que los niños perciben que este espacio fue creado para ellos y se apropian de ello como sujetos críticos que colaboran en su construcción y / o la disputan con los adultos. Y esta sensación de tener la "Ciranda" como un espacio suyo les autoriza a proponer mejoras para su realización.

Palabras clave: Niño. "Ciranda infantil". Investigación con niños. Rural. MST.

\section{INTRODUÇÃO}

pesar dos diversos avanços para a compreensão dos processos de socialização
e de metodologias de pesquisa com crianças, de acordo com Sarmento
(2005, 2007), existe ainda uma "ocultação da criança" em nossa sociedade.
Para o autor, os conhecimentos produzidos "sobre" as crianças têm se mostrado
adultocentrados, de forma a descrevê-las por traços de negatividade, como a
ausência, a incompletude e o não reconhecimento de sua condição de "ser humano
completo" (Sarmento, 2007, p. 33). Geralmente, os estudos colocam as crianças
em posições subalternas em relação aos adultos, atribuindo-lhes imagens que 
não condizem com sua complexidade social. A partir dessa construção histórica do conhecimento "sobre" a criança, refletida e ao mesmo tempo produzida por práticas sociais, econômicas e políticas, há uma construção simbólica, com bases ideológicas, que significa a criança como incapaz de ser informante confiável, portanto, sem direito à fala ou à escuta.

Müller e Hassen (2009, p. 471) destacam que, a partir da década de 1970, ocorre a ascensão de "novos direcionamentos nos estudos da infância”. Recorrendo a Prout e James (1997), apontam como marco inicial dessa corrente os estudos de Ariès (1981).

Uma das áreas de destaque nessa perspectiva é a chamada Sociologia da Infância, que surge na década de 1980. Corsaro (2011) apresenta a emergência da área como uma contraposição às perspectivas que ele identifica como funcionalistas, predominantes nos estudos sobre infância, até aquela década, na Sociologia. A concepção de criança atribuída à perspectiva hegemônica funcionalista era a de "alguém apartada da sociedade, que deve ser moldada e guiada por forças externas, a fim de se tornar um membro totalmente funcional" (Corsaro, 2011, p. 19). Nesse sentido, a socialização é vista como um processo em que as crianças "se adaptam e internalizam a sociedade" (Corsaro, 2011, p. 19).

A partir dos "novos direcionamentos nos estudos da infância", ocorre um destaque especial à capacidade não apenas de reprodução, mas de (re)construção de cultura pela criança, o que deriva em uma concepção de criança como ator social, um agente ativo no processo sociocultural (Corsaro, 2011; Sarmento, 2005). Müller e Hassen (2009) destacam que a Sociologia, ao adotar como objeto de estudo a infância, enfoca "as condições de vida das crianças e seus diferentes contextos sociais e históricos” (p. 473), negando e contrapondo-se a um conceito único e universal de infância. Diversas correntes explicativas emergem dessa perspectiva e, segundo as autoras, todas rompem com "o modo limitado com que a sociologia concebia a infância” (p. 473). Contudo, apesar de reconhecerem a importância da Sociologia da Infância nos estudos, nas práticas e nas concepções sobre criança, ao mesmo tempo, destacam que ela assume uma compreensão um pouco restrita, que compreende a "criança como um ser unicamente social" (p. 473). Defendem, assim, a relação de várias abordagens para a compreensão do sujeito criança na Contemporaneidade, a partir de diferentes áreas de conhecimento.

$\mathrm{Na}$ Psicologia do Desenvolvimento, destacamos as contribuições de Castro (2001) para esse debate atual. Analisando a área, a autora critica a presença hegemônica de uma visão "normativa" da infância, na qual o desenvolvimento é concebido em etapas relacionadas à idade. O ápice do desenvolvimento 
ocorreria na etapa adulta, compreendida como a idade da razão, caracterizada pela autonomia e pelo saber. Já as crianças seriam concebidas como um "vir a ser", em um momento de "desrazão" e de "débito social e cultural" (Castro, 2001). De acordo com a autora, essa perspectiva contribui para uma sociedade adultocêntrica, caracterizada por uma relação hierárquica entre adultos e crianças. Contrariamente, a autora propõe uma forma diferenciada de se compreender o desenvolvimento humano, denominada por ela de perspectiva "antidesenvolvimentista" (Castro, 2001). Defende a existência de uma relação mútua de dependência entre adultos e crianças, sendo que as diferenças entre eles não deveriam ser consideradas como fator hierarquizante das relações, pois as variações socioetárias possibilitam diferentes atuações nos contextos, influenciando a formação de subjetividades. Assim, considera a criança em sua potência criativa, capaz de intervir em seus contextos. Alinhados às proposiçôes recentes nos estudos "sobre" e "com" as crianças, compreendemos a criança como participante ativa no processo de construção e apropriação do mundo social, (re)criando e (re)significando espaços e relações em um movimento dialético marcado, dentre outras, por questôes subjetivas, sociais, históricas, econômicas, de gênero e também etárias.

Assim, refletir sobre as infâncias construídas no nosso momento histórico significa analisar questôes geracionais, mantendo um olhar sobre os diferentes aspectos subjetivos e sociais que as configuram. A criança é compreendida como um importante interlocutor, que informa sobre suas vivências, relaçôes e vida, o que nos propicia compreender modos específicos e diferenciados de viver as infâncias a partir de seus protagonistas. Como destaca Cruz (2008), os desejos e pontos de vista das crianças:

Podem ser bastante heterogêneos, já que, além de expressarem as peculiaridades da história de cada uma delas, também são marcadas pelas experiências concretas vividas em determinado contexto e momento histórico profundamente influenciado pelos lugares que as crianças e suas famílias ocupam na sociedade, assim como pelo pertencimento a determinado gênero, etnia e cultura. Afinal, em todos os tempos, são muito diversas as infâncias possíveis aos seres humanos, mesmo àqueles que convivem na mesma sociedade (p. 13).

Entre as diferenciadas infâncias, temos concentrado nosso interesse nos modos de vida das crianças de assentamentos rurais vinculados a movimentos sociais, na tentativa de compreender as formas distintas e, ao mesmo tempo, semelhantes em relação a outras infâncias, de participação na família, na escola e na comunidade. Partimos do reconhecimento de uma dialética tanto entre o geral e o local (que circunscreve as diferenças e as aproximações entre as experiências das crianças em 
diferentes contextos) como entre adultos e crianças. Nessa perspectiva, na (re) produção da cultura, há uma zona de compartilhamento entre as produções dos adultos e das crianças, entendidos como coagentes do processo interativo, assim como zonas próprias das criações desses segmentos geracionais.

Os territórios rurais brasileiros são múltiplos e marcados por processos gerais e específicos de relação com a produção econômica, os recursos naturais, a organização familiar, as práticas educativas junto às crianças e as dinâmicas geracionais. Em alguns assentamentos rurais, outra diferenciação é vivida quando da presença, no seu interior, de movimentos sociais de luta pela terra e pela reforma agrária, compondo assim novas dinâmicas no processo de inserção das crianças na vida do assentamento.

Nos assentamentos vinculados ao Movimento dos Trabalhadores Rurais Sem Terra (MST), são propostas atividades com as crianças, organizadas em torno do que se chama Ciranda Infantil.

Para Rossetto (2009), nas cirandas, busca-se propiciar que as crianças vivenciem o assentamento rural como sujeitos que participam ativamente, juntamente com suas famílias, das lutas do movimento social pela terra. Vinculadas às demais ações desse movimento social, as cirandas infantis surgem como resposta à demanda da mulher/mãe do MST no compartilhamento do cuidado de suas crianças para que possam participar politicamente das atividades coletivas.

Nessa conjuntura, as cirandas surgem, em 1997, definidas pelo MST como:

Espaços educativos intencionalmente planejados, nos quais as crianças aprendem, em movimento, a ocupar o seu lugar na organização de que fazem parte. É muito mais que espaços físicos, são espaços de trocas, aprendizados e vivências coletivas (Movimento dos Trabalhadores Rurais Sem Terra [MST], 2004, p. 37).

Rossetto e Silva (2012) afirmam que, a partir das experiências dessas ações e proposições do MST, as cirandas, inicialmente destinadas às crianças de até 6 anos de idade, ampliam a faixa etária para os 12 anos e procuram abarcar o conjunto das crianças dos assentamentos e acampamentos vinculados a esse movimento. Portanto a Ciranda Infantil se materializa como um espaço/ tempo de educação não formal, podendo ser permanente (realizada nas escolas, acampamentos, assentamento e centros de formação) ou itinerante (realizada em marchas e encontros). Constituem-se como um espaço/tempo para a construção das identidades das crianças, em processos de interação com seus pares de faixas etárias diferenciadas e com a comunidade. De acordo com o MST, trata-se de uma prática educativa estruturada por membros da própria comunidade, cuja tarefa é organizar e propiciar momentos para que as crianças possam vivenciar suas infâncias por meio de atividades lúdicas. 
Por estarem inseridas nas propostas educacionais do MST, as cirandas incorporam seus princípios orientadores. Para Dalmaz e Scarmocin (2013):

A proposta educacional do MST se constituiu com o objetivo de despertar nos semterra o sentimento de pertencimento, isto é, a consciência política e ideológica do que é ser um trabalhador/a, ou criança sem-terra e não somente da necessidade de atender às crianças oriundas das famílias acampadas e assentadas (p. 8).

Assim, a formação nas cirandas infantis intencionalmente pretende abarcar várias dimensões da vida da criança, inclusive a política. Nesse contexto, as crianças podem experimentar o protagonismo de ações e reflexões sobre situaçõos de seu cotidiano e, assim, contribuir também para a construção de suas identidades no espaço da comunidade rural (MST, 2004).

Arenhart (2004) destaca algumas características da Ciranda do MST, que a colocam como um espaço que se contrapõe à formação da criança na sociedade capitalista. São elas: a participação infantil; a valorização do coletivo; o cuidado mútuo; a construção de valores e símbolos que levam ao sentimento de pertença social; a solidariedade; o cultivo da memória social; o respeito à natureza; a valorização do ser humano como sujeito histórico.

Em relação ao papel dos adultos nas cirandas infantis, nos documentos orientadores da ação dos educadores do MST, estimula-se a promoção do desenvolvimento da criança "com autonomia, criticidade, criatividade e espírito de cooperação, como cidadā" (MST, 2004, pp. 39-40). Propõem, portanto, uma forma de olhar para a criança e o jovem que provoca a abertura do adulto para a sua escuta, de forma a valorizar, ao menos nos documentos, suas opiniōes e açôes.

As cirandas inscrevem-se em interpretações que buscam compreender o assentamento e os assentados para além das vinculações identitárias marcadas pela dimensão produtiva e econômica ou pela relação com o movimento social. Essa perspectiva considera o assentamento como lugar de vida e, portanto, os assentados como pessoas imersas em múltiplos tempos e espaços, que participam de diversas interaçôes sociais e intergeracionais. Essas interaçōes circunscrevem papéis que se sobrepóem, competem ou se afirmam, numa trama identitária bastante complexa. Assim, o assentamento e a Ciranda constituem, para as crianças, possibilidades de convivência e de partilha de várias gerações e lócus de aprendizado coletivo.

Se essas características da Ciranda são sustentadas na literatura ou pelo movimento social que a criou, resta saber, numa vertente que valoriza as crianças como sujeitos sociais, o que elas próprias pensam sobre esse espaço. Dada a 
pouca visibilidade, na ciência e na política social, das crianças e da infância de contextos rurais, acredita-se que as experiências que as colocam como foco de suas ações constituem-se como situações privilegiadas de investigação. Sabe-se que a proposição de ações para a criança não garante a efetivação de suas concepções. Há que se compreender o que dizem as crianças sobre as cirandas e investigar se elas, como sujeitos teoricamente ativos, estariam estimuladas a apresentar alguma crítica ou sugestão. Nessa direção, o trabalho teve como objetivo ouvir as próprias crianças sobre o espaço da Ciranda, buscando compreender as significaçóes por elas construídas sobre as atividades e relações nesse espaço.

\section{MÉTODO}

\subsection{Contexto da pesquisa e dos participantes}

A Ciranda investigada nesta pesquisa é permanente e ocorre desde o momento em que as famílias se organizavam como um acampamento rural, em 2003. O local era uma fazenda situada sobre uma área de recarga do Aquífero Guarani, na fronteira entre a zona urbana e rural do Município Ribeirão Preto-SP. A fazenda foi ocupada em 2003 pelo MST, após requisição de desapropriação da área para fins de reforma agrária. A requisição ao Instituto Nacional de Colonização e Reforma Agrária (INCRA) foi feita em 2000, pela Promotoria de Justiça do Meio Ambiente e Conflitos Agrários, devido a passivo ambiental. A fazenda foi desapropriada em dezembro de 2005 por meio de decreto presidencial, iniciandose os procedimentos burocráticos para a constituição do assentamento.

No momento da pesquisa, o assentamento era dividido em quatro diferentes grupos vinculados a quatro movimentos sociais de luta pela reforma agrária. A população total era de aproximadamente 520 famílias, sendo o assentamento em que a pesquisa foi realizada composto por 264 famílias. O modelo de produção adotado é o sistema agroflorestal (Saf), por meio de áreas cooperadas de plantio, o que engendra particularidades nas formas de efetivação, na organização dos sujeitos e atividades, e na função que o assentamento cumpre no contexto local.

O assentamento não dispunha de serviços básicos, como unidades de atendimento em saúde, transporte público e equipamentos educacionais. Para frequentarem a escola, as crianças usam o transporte público municipal, em uma trajetória de cerca de uma hora entre o assentamento e as escolas, que são situadas na periferia da cidade.

Ao longo de sua existência, a Ciranda assumiu diferentes configurações. No início da pesquisa, ela era realizada a cada 15 dias e, posteriormente, passou a 
acontecer todos os sábados, no período da manhã. Também foi realizada em diferentes lugares do assentamento, mas, a partir de um questionamento das próprias crianças, fixou-se a sua realização na área da antiga sede da fazenda. As cirandas eram organizadas pelos próprios assentados, denominados de "cirandeiros". Dela participavam aproximadamente 30 crianças e jovens, dos 3 aos 17 anos de idade, sendo que o número de crianças no assentamento era maior do que o que frequentava a Ciranda. A ausência se dava, em alguns casos, pelas longas distâncias internas do assentamento e pelo fato de a participação das crianças, muitas vezes, ficar condicionada à autorização ou condução dos próprios pais ou responsáveis, já que não havia transporte coletivo em seu interior.

As atividades iniciavam-se às oito horas da manhã. Havia um lanche às dez horas, e, ao meio-dia, as atividades eram encerradas. A Ciranda era iniciada por meio de uma dinâmica denominada "mística", a qual podia contar com o uso de diferentes linguagens e recursos que aqueciam o coletivo para as atividades a serem realizadas naquele encontro. Entre as atividades, destacam-se ações que envolviam a criatividade das crianças como a confecção de desenhos, de histórias e de músicas; experimentações artísticas, como o teatro e dança; jogos e esportes; utilização de brinquedos diversificados; vivência de plantio de sementes.

A inserção dos pesquisadores na Ciranda pesquisada se deu em meados de 2007, a partir de uma demanda de membros da comunidade do assentamento que solicitaram o auxílio na formação dos cirandeiros para o exercício de suas atividades. Um projeto de extensão universitária foi então iniciado e se estendeu até o ano de 2013. Por meio do acompanhamento das atividades de extensão com os adultos e as crianças, questóes de pesquisa passaram a emergir. A pesquisa aqui relatada teve seu objeto circunscrito nesse contexto e foi motivada pela necessidade de compreender os significados construídos pelas crianças sobre a Ciranda, as relações e as práticas ali desenvolvidas. A pesquisa possibilitou-nos, como membros externos e corresponsáveis pela formação dos educadores leigos, uma avaliação das práticas desenvolvidas a partir da perspectiva das próprias crianças.

\subsection{Participantes}

Participaram seis crianças de 6 a 12 anos (duas de cada idade) moradoras do assentamento rural, assim distribuídas: $\operatorname{Marcos}^{1}$ e Victor, de 10 anos de idade; Marta e Sabrina, de 11 anos; Elisa e Letícia, de 12 anos. O critério de escolha das crianças foi o maior tempo de participação em atividades da Ciranda e no assentamento. Essa seleção foi feita com o auxílio dos adultos que acompanhavam

\footnotetext{
1 Como acordado com pais e crianças no termo de consentimento livre e esclarecido, todos os nomes apresentados são fictícios. A pesquisa foi aprovada pelo Comitê de Ética em Pesquisa da Faculdade de Filosofia, Ciências e Letras de Ribeirão Preto (FFCLRP) - Universidade de São Paulo (USP).
} 
a Ciranda no assentamento, desde seu início. Todas as crianças participantes da pesquisa estavam no assentamento desde sua primeira ocupação. Todos eram bastante assíduos na Ciranda e tinham um histórico de relação continuada com este espaço/tempo.

\subsection{Instrumentos, técnicas e procedimentos de construção e análise do corpus}

Como destacado por Rossetti-Ferreira et al. (2004), o primeiro momento para o desenvolvimento da pesquisa é a "vivência inicial", ou "mergulho" do pesquisador no contexto da pesquisa. Esse momento prevê o compartilhamento do espaço, das interações e relaçôes, com vistas a apreender os diversos elementos envolvidos e a obter uma visão panorâmica da situação pesquisada. $\mathrm{Na}$ pesquisa com crianças, necessita-se também de uma aproximação que permita a familiarização destas com o pesquisador, na conquista de confiança para se expressarem. No caso da pesquisa, já havia uma relação estabelecida entre crianças e pesquisadores, mediada pelas atividades lúdicas desenvolvidas pelo projeto de extensão.

Campos (2008), apoiada em Mann e Tolfree (2003), aponta que, na investigação com crianças, a pesquisa deve "empoderar" a criança para que ela constitua e represente "seu mundo social" (Campos, 2008, p. 38). Visando a alcançar esse objetivo, deve-se utilizar de instrumentos adequados à idade das crianças, considerando seu ambiente cultural. Sobre a ética na pesquisa com crianças, a autora afirma que há que se ter cuidado para não expor ou gerar vulnerabilidade à criança, assim como não a submeter a situações e procedimentos que gerem sofrimento e estresse (Campos, 2008). Todas as informaçôes relativas à vivência do pesquisador com as crianças foram registradas em um "diário de campo".

Para a compreensão das significações das crianças sobre a Ciranda, foram associados os usos de entrevistas, fotografias e fantoches. Segundo Müller (2006), a fotografia como técnica de pesquisa, ao partir de materiais produzidos pelas próprias crianças, possibilita que elas apresentem suas percepções e sentidos sobre os contextos que as cercam, distanciando-se de outras formas usuais de escuta que, muitas vezes, privilegiam os conhecimentos adultos e não os infantis.

Para a construção do corpus empírico, foram realizados, no total, três encontros com cada criança, sempre individualmente. No primeiro encontro, foi disponibilizada uma câmera fotográfica para a criança. As instruções dadas às crianças foram de que deveriam fotografar o que se apresentava como mais significativo na Ciranda, podendo ser objetos, materiais, espaços, pessoas e 
situações que julgassem positivas ou negativas. Foi solicitado que as crianças representassem a Ciranda Infantil como "se elas fossem apresentar a Ciranda para alguém por meio dessas fotos”. As fotografias foram registradas pelas crianças, sem a interferência do pesquisador.

No segundo encontro, as fotografias foram tomadas como ponto de partida para uma conversa com as crianças, abordando os diferentes espaços retratados. As conversas foram audiogravadas e transcritas na íntegra pelo pesquisador.

No terceiro e último encontro, realizado individualmente, a conversa foi retomada com a criança, sendo introduzidos os fantoches para a discussão sobre o espaço da Ciranda com as crianças menores (10 anos) como forma de trazer o lúdico às entrevistas. $O$ fantoche representava uma criança recém-chegada ao assentamento e que não conhecia a Ciranda. Solicitava-se que ela apresentasse a Ciranda a esse visitante do lugar.

Fundamentados pelos pressupostos teórico-metodológicos da perspectiva da Rede de Significações (Rossetti-Ferreira et al., 2004), no momento da análise do corpus empírico, buscou-se a identificação das significaçōes sobre a Ciranda, evidenciadas em apreciações, avaliações e comentários críticos. Como procedimento de análise, foram realizadas leituras do material produzido, acompanhadas pela identificação das significações produzidas pelas crianças, submetidas posteriormente a uma categorização. A análise primeiramente buscou evidenciar elementos singulares das crianças participantes e, depois, foram agrupados os elementos comuns ao conjunto das crianças participantes da pesquisa. Após identificar esses elementos comuns, essas falas foram agrupadas e divididas em duas categorias: Significados sobre a Ciranda; Avaliações e sugestóes para a Ciranda.

\section{RESULTADOS}

\subsection{Significados sobre a ciranda}

Encontramos, na fala das crianças, significados que descrevem a Ciranda Infantil como um "espaço lúdico", com destaque para atividades recreativas como: brincadeira, jogos, passeios, atividades culturais (teatro) e experimentações artísticas (dança, teatro e desenho). Marcos (10 anos) diz:

Pesquisador: [...] Então eu queria que você apresentasse a Ciranda pra essa menininha que acabou de chegar no assentamento. Faz de conta que ela não conhece nada. O que você falaria para ela? (referindo-se ao fantoche). 
Marcos: Lá tem brinquedo, brincadeiras, futebol. [...]

Pesquisador: E além do futebol, o que você mais gosta de fazer lá?

Marcos: A queimada.

Por sua vez, Sabrina (11 anos) relata:

Pesquisador: E o que você mais gosta de brincar lá [na Ciranda]?

Sabrina: De queimada [...]

Pesquisador: Você gosta de teatro, de dança?

Sabrina: Sim, só não gosto de fazer, eu tenho vergonha.

Pesquisador: Mas você participou do grupo do teatro...

Sabrina: Hã-hã! Porque tinha pouca gente.

As atividades lúdicas citadas por Marcos ("brinquedo, brincadeiras, futebol" e "queimada") assumem uma centralidade nas significaçôes sobre a Ciranda, o que deposita nesse espaço a responsabilidade por seu oferecimento. Além disso, as atividades artísticas (o teatro, a dança e o desenho) aparecem como possibilidades de vivenciar diferentes modos de expressão, inclusive de confronto com as dificuldades pessoais trazidas pelas crianças, por exemplo, a timidez.

Entre as atividades lúdicas, artísticas e esportivas, a prática do futebol emerge com bastante força na significação das crianças de todas as idades e sexo, embora seja mais presente para os meninos. Associada a essa prática, percebeu-se, nas significações das crianças, a presença de "disputas e conflitos" intergeracionais que extrapolam aqueles inerentes a esse jogo. Essa associação pode ser exemplificada pela disputa pelo local em que o futebol ocorre, conforme relato de Victor (10 anos).

Victor: Esses dias aí mesmo, não tinha campo ali mais. Arrancaram por causa que o cara começou a achar ruim que estava caindo [a bola] lá no meio do mato lá [no lote dele] e falava que ia plantar coisa lá; só que até hoje ele não plantou, ele plantou capim lá. [...] Aí, quando a gente ia lá pra jogar, ele já estava cheio de mato, carrapicho, cheio de mato. Aí eu e o Davi pegamos e fizemos [outro campo] aqui embaixo. Agora que a gente começou a jogar de novo bola ali.

Pesquisador: E o que ele costumava fazer?

Victor: Ele achava ruim, falava que caía, que não queria que jogava bola mais ali. Falou que se ver a gente jogando bola ali vai botar pra gente ir embora. Daí a gente pegou e não [...] aí ele pegou e falou nada mais, já tirou o campinho da gente dali e foi fazer ali em cima. 
As crianças assumem um papel ativo na negociação da ocupação do campo, cujos limites foram estabelecidos por elas, por meio das traves do gol, na divisa entre a área coletiva do assentamento e um lote individual de um assentado. Victor (10 anos), por exemplo, traz na conversa a insatisfação daquele assentado e assume, assim, um papel de reflexão sobre as divergências entre os interesses do assentado e das crianças, o que confere visibilidade às tensôes e às discussóes que se geram em torno da área onde ocorre o futebol.

As estratégias das crianças são de resistência e de enfrentamento às posições do assentado, demonstrando forte apropriação daquele lugar e o pertencimento a um coletivo que se forma pelo futebol. Ao mesmo tempo, Victor se sente encorajado e critica o uso que o assentado fazia no interior de seu próprio lote, num tom de insatisfação em relação aos argumentos apresentados pelo assentado e à forma como seu lote é tomado pelo capim. Também Letícia (12 anos) destaca o mesmo fato e o descreve em termos de conquista:

Pesquisador: Aqui você tirou [fotos] dos meninos jogando bola no campinho?

Letícia: É, eu também gosto de jogar bola, e aí é onde eu mais chamo atenção, porque eles [os meninos] são muito bons, e, desde criança, alguns deles vinham na Ciranda e eles pediam, e lutaram pra ter um campo aí, e agora tem. Acho bem importante.

Diante do depoimento de Victor e de Letícia, fica clara a reivindicação por espaço e a crítica às atitudes dos adultos que confrontam com as atividades e pautas das crianças. Além de Victor não ver como problema a prática do futebol no lugar de conflito, ele ainda propóe soluçôes de melhoria do espaço para que as crianças possam ter um maior conforto ao praticar o esporte, como um novo gramado que poderia ser plantado por eles mesmos. "A grama aqui a gente vai tentar plantar, porque, sem grama [...], quando a gente cai machuca, rala muito, quando com a grama é difícil machucar" (Victor).

Outra significação que emerge na conversa com as crianças é da Ciranda como um "espaço de socialização". Ou seja, um espaço de interações em que os indivíduos se constituem por meio dos grupos, sendo que o comportamento de cada sujeito exerce influência sobre o comportamento dos outros e do coletivo. Sabrina (11 anos) diz:

Pesquisador: E essa foto aqui, por que você tirou?

Sabrina: Essa aqui eu tirei porque eu acho que é a união das pessoas. [...]

Pesquisador: Por que você acha que elas são unidas? O que tornam elas unidas na Ciranda? É o brincar junto? O que você acha?

Sabrina: É, eu acho que o brincar junto e as amizades, né. 
A fotografia mencionada por Sabrina registra o momento em que uma atividade era realizada pelo conjunto de adultos, jovens e crianças. Ao utilizar a palavra "união", assim como "amizade", Sabrina atribui tons também emocionais às suas significaçôes sobre a Ciranda e deposita na atividade de "brincar junto" o motivo partilhado com o pesquisador para a vinculação de pessoas de diferentes idades na Ciranda.

Outra significação apresentada pelas crianças sobre a Ciranda relaciona-se a sua função na construção de relações socioambientais, isto é, na "mediação entre as crianças e o ambiente natural". Cabe destacar que o modelo de assentamento adotado é de Saf, e as questóes ambientais são, portanto, tema recorrente e cenário para as atividades e a constituição das crianças, o que podemos verificar na fala de Letícia (12 anos):

\section{Pesquisador: E essa árvore aqui?}

Letícia: Ah, essa árvore foi a gente que plantou. Juntou um monte de crianças da Ciranda e a gente plantou um monte de arvorezinhas dessas.

Pesquisador: E que você acha disso?

Letícia: Eu acho uma boa ação pra natureza, plantar mais árvores.

A experiência de participação no plantio de árvores e de cuidado com a natureza aparece para Letícia como uma boa ação, o que a vincula também moralmente à Ciranda e, principalmente, às açôes do movimento na efetivação do modelo de assentamento que ele planeja naquela localidade. Essa mediação promove a relação da criança com uma significação ainda mais ampla acerca de sua participação em relação às atividades de preservação e recuperação da natureza naquele espaço.

Outra significação da Ciranda a identifica como um local que "promove aprendizagens e conhecimentos” de diversas ordens. Tais conhecimentos estão relacionados desde a natureza e a como preservá-la, a assuntos como a luta pela terra. No trecho a seguir, Sabrina (11 anos) explicita uma das ações promovidas no interior da Ciranda, por meio de um projeto que busca aproximar as crianças ao contexto de produção agroflorestal. Um boneco denominado Safinho foi usado para mediar as conversas e os plantios em uma pequena área de Saf específica da Ciranda.

Pesquisador: E o que é a Ciranda pra você? O que você faz lá?

Sabrina: Eu brinco e aprendo também, né?

Pesquisador: $\mathrm{O}$ que você aprende lá? 
Sabrina: Quando eu cheguei, eu aprendi a cuidar da natureza, né? Não jogar plástico nem nada, e agora a gente tá aprendendo do Safinho.

Pesquisador: E quando você chegou, [...] como eram essas atividades, o que os cirandeiros faziam?

Sabrina: Eles pegavam nós e levava lá na mina que tem lá, e aí eles faziam atividades lá, falavam pra nós que planta que era, e aí nós aprendíamos essas coisas.

É possível perceber o caráter pedagógico dado por Sabrina a esse espaço, devido às atividades proporcionarem novos ensinamentos e aquisições para sua vida.

Já Letícia, ao registrar a foto do curral, apresenta uma significação que vincula a Ciranda à experiência de situações próprias de crianças de movimentos de luta pela terra, que vivenciam ocupações, deslocamentos e sentimentos particulares. $\mathrm{O}$ antigo curral da fazenda abrigou acampados quando da ocupação da área e transformou-se em "Curral Cultural", servindo a várias atividades dos assentados, inclusive da Ciranda.

Letícia: Nossa, saber que eu dormia aí [curral] [...] Porque quando eu vim pra cá, eu tinha que dormir aí, então isso aí também é uma lembrança [...].

Pesquisador: Você e mais quem?

Letícia: Eu, minha mãe, meu pai e muita gente que desistiu de lutar pela terra, que já foi embora.

Pesquisador: O que seria esse seu "lutar pela terra"? Você acha que a Ciranda tem relação com isso?

Letícia: Ah, tem. A Ciranda que me aconselhou a lutar junto com a minha mãe, porque eu não gostava muito, aí a Ciranda falava. Às vezes, eu fugia da Ciranda porque eles falavam muito comigo e eu ficava nervosa e fugia.

A Ciranda como um espaço de mediação entre as crianças e a decisão de sua família de lutar pela reforma agrária, assim como em relação ao próprio movimento social, aparece de forma tensa e conflituosa na fala de Letícia, revelando medos, estranhamentos e resistência àquela nova realidade e à própria Ciranda.

Resumidamente, as significações sobre a Ciranda construídas pelas crianças compõem um quadro que a define como um espaço lúdico, de vivência de disputas e tensões com seu entorno, de construção e fortalecimento de relações de amizades, de mediação com a natureza e de aprendizagens diversas. 


\subsection{Avaliações e sugestóes para a Ciranda}

Ao conversarmos com as crianças, elas avaliam a Ciranda e apresentam preferências e críticas em relação à forma como ela acontece.

De modo geral, são apresentados como "aspectos positivos da Ciranda Infantil" o lugar onde ela é realizada, as atividades que ela promove, os passeios, experimentaçōes artísticas e as competiçōes. Sabrina, de 11 anos, diz:

Pesquisador: [...] E qual é a sua melhor lembrança da Ciranda? [...]

Sabrina: O dia que a gente fez um teatro, que as meninas fizeram três grupos. Aí cada grupo fez uma coisa. O nosso grupo fez o da dança, outras pessoas fizeram o da peça e outro que eu não lembro o que fez, aí nós ficamos em segundo lugar. Aí esse dia foi o que me marcou muito.

Pesquisador: Foi uma competição, então?

Sabrina: É.

As crianças também apresentam "aspectos negativos" da Ciranda. Alguns destes referem-se à falta de estrutura, como destaca Victor, de 10 anos:

Victor: Aí tá vendo essas partes aqui [grama falhada], ó!? A maioria dessas partes aqui tem pedra, aí nós vamos ter que limpar. Uma vez eu estava jogando e eu destronquei dedo; meu dedo inchou, [...] é perigoso. Uma vez, o moleque estava jogando bola ali, [...] sei lá o que ele fez, sei que ele quebrou o pé, quebrou o pé duas vezes.

Pesquisador: Perigoso mesmo.

Victor: É, perigoso! Está vendo essas partes do mato maior aqui? Achava que [se] nós pegasse, arrumasse um pouco de grama, cortava e colocava a grama no lugar dele [mato maior]. Eles [matos] atrapalham quando a gente vai driblar, faz a bola ficar pesada.

A falta de estrutura adequada é apontada por Victor no local em que o futebol é realizado. $\mathrm{O}$ espaço chega a ser referido como "perigoso" por não ter um gramado adequado. Por meio dos relatos, é possível identificar também situaçóes de questionamento a partir de suas perspectivas, no diálogo e em complementação ao que avaliam como negativo. Assim, elas exercem diante da pesquisa um papel crítico ao explicitar tensões e expor sugestões e ideias de acordo com suas necessidades e concepções, como podemos verificar também nas falas de Elisa, de 11 anos:

Elisa: Eu acho que deveria ter mais árvore né, aquele lugar ali. Porque eles estavam caçando sombra pra eles poderem sentar.

Elisa: Esse aqui é o banheiro, que, às vezes, eu vejo as meninas indo pra aquele banheiro, eu acho que também deveria construir um banheiro aqui pra nós todos da Ciranda. 
Elisa: Aqui é que eu acho que deveria fazer um banco pra eles sentarem, porque muitos sentam no chão. Aí se fizessem um banquinho ali ficaria bem legal.

O banheiro também é uma questão levantada por Letícia, ao registrar fotograficamente o local, para mostrar sua insatisfação. Depois de ser perguntada se todas as crianças utilizavam o local, ela responde que "alguns fazem até no mato", para indicar que outras crianças preferem não o utilizar.

A questão da falta de transporte para levar as crianças que moram longe até a Ciranda é tratada por Elisa, de 12 anos, e Sabrina, de 11, ao dizerem que isso prejudica a presença de algumas crianças:

Pesquisador: Você acha que todas as crianças do assentamento vão à Ciranda?

Sabrina: Vão quase todas, mas tem muitas que moram longe e que não podem ir também.

Pesquisador: E você acha que a Ciranda atinge todas as crianças do assentamento, você acha que todas as crianças sabem o que é?

Elisa: Não! Muitos não vêm.

Pesquisador: E por que você acha que eles não vêm?

Elisa: Por que é muito longe, e os pais não têm carro pra vir.

Pesquisador: E como você acha que poderia melhorar isso?

Elisa: Eu acho que a gente deveria batalhar pra poder comprar uma Kombi, poder passar pra pegar as crianças.

A Ciranda é realizada na sede da fazenda e, embora central, as crianças que moram nos limites do assentamento ficam distantes desse local. Vinculada a essa disposição geográfica e à falta de transporte coletivo no assentamento, Elisa vislumbra a possibilidade de um veículo que conduza as crianças até a Ciranda, tornando-a mais acessível ao coletivo de crianças assentadas.

Marta, de 11 anos, por sua vez, critica o fato de a Ciranda ser realizada apenas com as crianças do assentamento vinculado ao MST. Como já dissemos, existem outros três movimentos sociais distribuídos territorialmente na fazenda. Marta gostaria que a Ciranda fosse estendida a todas as crianças. Também o horário de início foi uma de suas críticas:

Pesquisador: Você acha que a Ciranda atinge todas as crianças do assentamento?

Marta: Não, porque algumas não vão. Porque as crianças do [nome do movimento social] acha que a Ciranda é só da outra parte, do MST. 
Pesquisador: Você gostaria que fosse mais gente?

Marta: É, e queria também que fosse um pouco mais tarde, porque oito horas da manhã é muito cedo.

Por fim, são apresentadas sugestões sobre as "atividades realizadas" na Ciranda Infantil. Referem-se ao modo, ao espaço das atividades e, também, à incorporação de novas atividades. Letícia, de 12 anos, propõe um espaço em que haja maior contato com a natureza:

Pesquisador: Hoje a Ciranda acontece também no curral e na própria sede, né? Onde você prefere que a Ciranda seja feita?

Letícia: Eu prefiro debaixo da árvore.

Pesquisador: Por quê?

Letícia: Porque é sombra, é uma coisa natural. Às vezes, lá tem sujeira, atrapalha muito [...]

Pesquisador: E diante de tudo isso, tem alguma coisa que queira complementar? Algo que pode melhorar a Ciranda? Alguma atividade que você acha que está faltando ou que poderia ter mais $[\ldots]$ ?

Letícia: Você diz alguma brincadeira?

Pesquisador: É, alguma coisa que você queira mudar [...].

Letícia: Eu queria que tivesse pelo menos uma bola, porque muitos que vão lá também gostam, e a bola que tinha lá era desse tamanhinho, então tinha que ter uma bola, porque eu gosto muito de esporte.

Verifica-se o desejo de que as atividades em área coberta fossem feitas em meio aberto, fato que é partilhado com Elisa, que sugere "debaixo do pé de tamarindo". Ao relembrar vários momentos da Ciranda, Letícia apresenta também a necessidade de alguns materiais esportivos. Dicas de novas atividades foram levantadas por Marcos, que gostaria de praticar o "basquete". Aumento na frequência de passeios e gincanas foi sugestão apresentada principalmente por Sabrina.

As propostas apresentadas relacionam-se a melhorias das condições estruturais do espaço físico, ao acesso à Ciranda, aos tempos e à diversificação das atividades.

\section{DISCUSSÃO}

As significações das crianças sobre a Ciranda a retratam como um importante espaço de construção de relações socioambientais e intergeracionais, além de 
promoção de aprendizagens de diversas ordens. A pesquisa mostrou a importância afetiva, lúdica e de referência pessoal que o projeto tem para as crianças, o que justifica, inclusive, a existência de disputas com os adultos. $\mathrm{Na}$ avaliação sobre as atividades, posicionam-se como sujeitos ativos e críticos, apresentando sugestóes que expressam necessidades de mudanças, desejos e utopias. Essa expressividade indica um processo de apropriação daquele espaço pelas crianças. É o sentimento de ter o projeto como espaço próprio que os autoriza a propor melhorias ao local e, ou, às condições estruturais existentes e a se apresentarem como protagonistas daquele lugar e das relações ali desenvolvidas. Essa expressão crítica das crianças relaciona-se também às vivências próprias de pertencimento a um movimento de luta pela terra, mediadas pelas açôes da Ciranda e dos cirandeiros.

$\mathrm{Na}$ mediação que a Ciranda faz entre a criança, o movimento social e o socioambiente do assentamento, as crianças são introduzidas no projeto maior dos assentados. Esse fato extrapola os limites geracionais, uma vez que a mediação realizada pela Ciranda vincula as crianças às práticas dos adultos na construção daquele espaço. Essa relação intergeracional implica as crianças no cuidado com o assentamento, nas metas estipuladas pelos assentados para a efetivação do modelo agroecológico e na vivência partilhada de pertencimento a um movimento de luta pela terra.

Em relação à avaliação da Ciranda, as questôes negativas levantadas corroboram outros estudos. Dalmaz e Scarmocin (2013) apontam:

Embora sejam objetivos relevantes para o desenvolvimento de uma proposta educativa direcionadas às crianças do campo, como mencionamos, as Cirandas Infantis ainda apresentam muitos limites, pois sua estrutura física nem sempre atendem as necessidades das crianças (p. 30).

Os esforços dos assentados na realização de Cirandas, mesmo em condições físicas insuficientes, revelam um compromisso com a infância e, ao mesmo tempo, sua efetivação circunscrita pela ausência de políticas que garantam estrutura e de condições para a efetivação dos assentamentos da reforma agrária como espaços de vida.

Em estudo realizado por Pereira e Guzzo (2014), ouvindo crianças que participam de cirandas do MST sobre seu processo de conscientização e fortalecimento, as autoras afirmam:

As cirandas infantis se apresentam como espaço onde os Sem-Terrinhas podem compartilhar experiências de realidades semelhantes, criar reflexões e ações acerca desta, construir uma identidade coletiva de ser Sem-Terra, se fortalecendo neste processo, tentando superar as condiçôes de vulnerabilidade que experienciam, corroborando com a concepção de fortalecimento apresentada neste trabalho. 
A experiência de um espaço que permita reflexões, ações e construção de uma identidade coletiva como fator de fortalecimento das crianças constitui um campo de partilhado entre as crianças que participam das cirandas. Na pesquisa, a apropriação desse espaço se manifesta por meio de uma vinculação positiva e de críticas para melhoria do espaço.

\section{CONSIDERAÇÕES FINAIS}

A pesquisa nos permite realizar considerações relativas a dois processos: à vivência de crianças particulares em áreas de assentamento; e à escuta das crianças nos projetos a ela destinados.

As significações construídas pelas crianças como sujeitos sociais estão em constante diálogo com as suas condições concretas de existência. As questóes aqui levantadas referem-se às construçôes de sujeitos que vivenciam as experiências de serem pertencentes a uma classe social, moradoras de um assentamento rural vinculado a um movimento social, sujeitos no processo de tensão, violência e disputa do campo brasileiro, participantes das cirandas infantis. Tais experiências, ao mesmo tempo em que as individualizam (pois são resultado da convergência de todas as experiências concretas de suas vidas, as quais não podem se repetir para nenhum outro ser humano), apontam para aspectos compartilhados com outras crianças que ocupam o mesmo lugar social. Assim, conhecer o que as crianças pensam sobre a Ciranda, uma proposta efetivada por um movimento social de luta pela reforma agrária, ajuda-nos a melhor conhecer parte da experiência de crianças que vivem em áreas de assentamento rural no País. Olhar para essas especificidades contribui na conformação dos conhecimentos sobre as diversas infâncias brasileiras.

Por sua vez, a escuta das crianças sobre um espaço realizado e pensado para elas se revela como um exercício fundamental para melhor compreendê-las em suas necessidades concretas e situadas.

As crianças participantes da pesquisa, ao se posicionarem como sujeitos com vontades próprias, atentam-nos, assim, para a necessidade de, nos estudos sobre e com a infância, e nos projetos criados para elas, ser permitida sua efetiva escuta, como protagonistas também que são de suas vidas. Trata-se de um convite para nos aproximar da vida cotidiana da criança a partir de sua própria perspectiva, considerando-a competente para avaliações complexas.

Dessa forma, para além de conhecer os sentidos e significações atribuídos pelas crianças aos espaços em que vivem, a pesquisa evidencia suas capacidades de engajamento dialógico, inclusive com o pesquisador, e de um olhar reflexivo acerca de suas necessidades e vontades, em interlocuções com sujeitos de diferentes idades. 


\section{REFERÊNCIAS}

Arenhart, D. (2004). A educação infantil em movimento: a experiência das cirandas infantis no MST. Pró-Posiçôes, 15, 175-189.

Ariès, P. (1981). História social da criança e da família. (2a ed.). Rio de Janeiro: Zahar.

Campos, M. M. (2008). Por que é importante ouvir a criança? A participação das crianças pequenas na pesquisa científica. In S. H. V. Cruz (Org.), A criança fala: a escuta de crianças em pesquisa. (pp. 35-42). São Paulo: Cortez.

Castro, L. R. (2001). Da invisibilidade à ação: crianças e jovens na construção da cultura. In L. R. Castro (Org.), Crianças e jovens na construção da cultura. (pp. 19-46). Rio de Janeiro: NAU/FAPERJ.

Corsaro, W. A. (2011). Sociologia da infância. (2a ed.). Porto Alegre: Artmed.

Cruz, S. H. V. (2008). Apresentação. In S. H. V. Cruz (Org.), A criança fala: a escuta de crianças em pesquisa. (pp. 11-31). São Paulo: Cortez.

Dalmaz, D. S. S. \& Scarmocin, D. (2013). A ciranda infantil do Movimento Sem-Terra no Brasil: formação política na infância. In Anais, Sifedoc-Seminário Regional e Fórum de Educação do Campo; 1 Seminário Regional de Educação do Campo, (Vol. 1), Santa Maria. Santa Maria: UFSM. Recuperado a partir de http://coral.ufsm.br/sifedocregional/images/Anais/Eixo\%2011/Dayane\%20 Santos\%20Silva\%20Dalmaz\%20e\%20Daiane\%20Scarmocin.pdf

Movimento dos Trabalhadores Rurais Sem-Terra. (2004). Educação infantil: movimento da vida, dança do aprender. São Paulo: MST. (Caderno de Educação, 12. Educação infantil).

Müller, F. (2006). Quando as crianças retratam a cidade e as suas infâncias. (Tese de Doutorado). Universidade Federal do Rio Grande do Sul, Programa de PósGraduação em Educação, Porto Alegre.

Müller, F. \& Hassen, M. N. (2009). A infância pesquisada. Psicologia USP, 20, 465-480.

Pereira, M. L. M. \& Guzzo, R. S. L. (2014, setembro). Ciranda infantil, a educação das crianças "sem-terrinhas": um desafio à psicologia. In Anais, 19 Encontro de Iniciação Cientifica; 4 Encontro de Iniciação em Desenvolvimento Tecnológico e Inovação, Campinas. Campinas: PUC Campinas. 
Prout, A. \& James, A. (1997). A new paradigm for the sociology of childhood? Provenance, promise and problems. In A. James \& A. Prout (Org.), Constructing and reconstructing childhood. (pp. 7-73). London: Falmer Press.

Rossetti-Ferreira, M. C. et al. (Orgs.). (2004). Rede de significaçôes e o estudo do desenvolvimento humano. Porto Alegre: Artmed.

Rossetto, E. R. A. (2009). Essa ciranda não é minha só, ela é de todos nós: a educação das crianças sem-terrinha no MST. (Dissertação de Mestrado). Universidade Estadual de Campinas, Programa de Pós-Graduação em Educação, Campinas.

Rossetto, E. R. A. \& Silva, F. T. (2012). Ciranda infantil. In R. Caldart et al. (Orgs.), Dicionário da educação do campo. (pp. 127-130). Rio de Janeiro: Escola Politécnica de Saúde Joaquim Venâncio/Expressão Popular.

Sarmento, M. J. (2005). Gerações e alteridade: interrogações a partir da sociologia da infância. Educação e Sociedade, 26(91), 39-48.

Sarmento, M. J. (2007). Visibilidade social e estudo da infância. In V. M. R. Vasconcelos \& M. J. Sarmento (Orgs.), Infância (in) visivel. (pp. 25-49). Araraquara: Junqueira e Martins. 